\title{
Mycotic pulmonary artery aneurysm secondary to septic emboli
}

\author{
Kellen A Knowles, ${ }^{1}$ Matthew Alvin, ${ }^{2}$ Emily Dunn ${ }^{2}$
}

'Johns Hopkins School of Medicine, Baltimore, Maryland, USA

2Department of Radiology, Johns Hopkins Hospital, Baltimore, Maryland, USA

\section{Correspondence to Dr Matthew Alvin, malvin2@jhmi.edu}

Accepted 29 November 2017

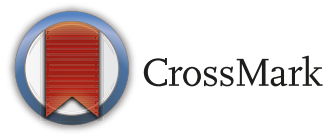

To cite: Knowles KA Alvin M, Dunn E. BMJ Case Rep Published Online First: [please include Day Month Year]. doi:10.1136/bcr-2017223439

\section{DESCRIPTION}

A 16-year-old girl with a medical history of tetralogy of Fallot repaired as an infant with right ventricle (RV) to pulmonary artery (PA) conduit presented to the emergency department with sudden onset fever of $38.4^{\circ} \mathrm{C}$, leg cramps and poor oral intake. At admission, she was hypotensive and tachycardic. Blood cultures were positive for methicillin-sensitive Staphylococcus aureus with white blood cell count of $6.1 \times 10^{\wedge} 9 / \mathrm{L}$ and $\mathrm{C}$ reactive protein 8.1 . An echocardiogram found evidence for moderate conduit stenosis and severe right ventricular hypertrophy, without occlusive vegetation directly visualised. An initial chest CT angiogram (CTA) confirmed these findings, showing an incompletely occlusive vegetation in the RV to PA conduit and multiple peripheral and nodular ground glass opacities, some with cavitation, scattered throughout both lungs consistent with septic emboli (figure 1A). After initiation of anticoagulation and antibiotics, her clinical symptoms steadily improved. Repeat blood cultures remained negative. Follow-up chest CTA performed 4 weeks later demonstrated persistent conduit vegetation as well as new aneurysmal dilation of segmental pulmonary arteries in the regions of previously noted septic emboli, indicative of mycotic aneurysm formation (figure 1B). An echocardiogram performed on the same day showed evidence for haemodynamically significant conduit stenosis and persistently elevated right ventricular pressures. Surgical revision of the conduit was performed. A chest CTA 2 weeks following surgery demonstrated stability of the

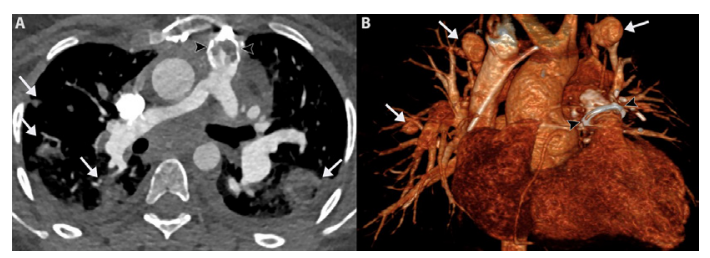

Figure 1 (A) Axial CT angiogram of the chest performed at admission shows confluent low attenuation filling defects within the RV to PA conduit vegetation (black arrowheads). Multiple, peripheral and nodular ground glass opacities, some with cavitation, are scattered throughout both lungs (white arrows) and are consistent with septic emboli. (B) Coronal 3-dimensional volume rendering of chest $\mathrm{CT}$ angiogram performed 4 weeks later shows several mycotic pulmonary aneurysms, observed in the regions of previously noted septic emboli (white arrows). The RV-to-PA conduit is also shown (black arrowheads). PA, pulmonary artery; RV, right ventricle. aneurysms. The immediate postoperative course was complicated by a pneumothorax and recurrent pleural effusions. After a short recovery, she was discharged home. Given her clinical improvement and overall stability of the aneurysms, it was determined that invasive therapeutic intervention carried greater risk than benefits. A conservative approach was pursued, and interval imaging was recommended to assess for stability.

Mycotic aneurysms are infections of the arterial wall that lead to weakening and dilation, resulting in outpouchings of the vessel. In those affecting the pulmonary arteries, Staphylococcus and Streptococcus are the usual culprits. There is a strong correlation between mycotic pulmonary artery aneurysms (MPAA) and congenital anomalies such as patent ductus arteriosus (PDA). Bartter et al hypothesised that the pathogenesis of MPAA in PDA is due to mechanical injury to the arterial wall from the PDA jet stream, leading to weakness and laying the groundwork for infectious involvement. ${ }^{1}$ In our literature review (including years 1974-2017), we found only 18 cases of MPAAs in paediatric patients (excluding pseudoaneurysms), with 15 having history of congenital heart defects. Four individuals succumbed to aneurysmal rupture before treatment. Children with congenital cardiac abnormalities, particularly those treated with indwelling devices, are especially at risk. A high index of suspicion of MPAA should be maintained for patients with cardiac abnormalities that develop bacteraemia or septic emboli.

With such high incidence of rupture, aggressive intervention has been advocated though there is still a precedence for conservative management. $^{2}$ Of late, treatment has more commonly involved coil embolisation or stent placement, though removal of lung segments and aneurysmal resection have also been reported. Five of the 18 patients in our literature review were treated conservatively with two of the cases reporting aneurysmal regression. Kreibich et al recommended indications for surgery and advocated for conservative treatment in asymptomatic patients with no significant pulmonary artery hypertension and stability of aneurysmal diameter. ${ }^{3}$ Imaging provides information that is often complementary to other diagnostic and clinical information, such as aneurysm size changes, which can directly influence the decision to treat. This highlights the importance of short interval imaging follow-up to monitor the size and status of the aneurysm and help guide clinical decision-making. 


\section{Learning points}

- Mycotic pulmonary aneurysms are rare entities in children that are highly associated with congenital heart disease.

- Management is controversial with short-interval imaging follow-up essential in guiding medical versus surgical decision-making.

Contributors KAK wrote the initial manuscript and edited it. ED and MA supervised and edited the manuscript to its completion.

Competing interests None declared.
Patient consent Obtained.

Provenance and peer review Not commissioned; externally peer reviewed.

(C) BMJ Publishing Group Ltd (unless otherwise stated in the text of the article) 2017. All rights reserved. No commercial use is permitted unless otherwise expressly granted.

\section{REFERENCES}

1 Bartter T, Irwin RS, Nash G. Aneurysms of the pulmonary arteries. Chest 1988;94:1065-75.

2 Wilson TN, Tew K, Taranath A. Multiple mycotic aneurysms of the pulmonary arteries resolving with conservative management: multislice CT examination findings. J Thorac Imaging 2008;23:197-201.

3 Kreibich M, Siepe M, Kroll J, et al. Aneurysms of the pulmonary artery. Circulation 2015;131:310-6.

Copyright 2017 BMJ Publishing Group. All rights reserved. For permission to reuse any of this content visit http://group.bmj.com/group/rights-licensing/permissions.

BMJ Case Report Fellows may re-use this article for personal use and teaching without any further permission.

Become a Fellow of BMJ Case Reports today and you can:

- Submit as many cases as you like

- Enjoy fast sympathetic peer review and rapid publication of accepted articles

- Access all the published articles

Re-use any of the published material for personal use and teaching without further permission

For information on Institutional Fellowships contact consortiasales@bmjgroup.com

Visit casereports.bmj.com for more articles like this and to become a Fellow 